\title{
Ambiguity of Phenomenological Method? \\ A Reply to John Osborne
}

\section{Robert Burch}

University of Alberta

What follows may prove to be a discussion at cross-purposes and so in the end more of a monologue than a genuine contribution to communal self-understanding. Osborne invites us to share in a "dialogue" on "the relation between research practice and phenomenological metatheory" (in press, p. 2), ${ }^{1}$ and having been concerned with aspects of this issue myself (cf. Burch, 1989, 1990, in press), I am happy to join in. Yet I come to the topic from the other direction to Osborne, that is, not as a practioner in a specific domain of human science research confronted with therapeutic exigencies, fending off positivist critics, and looking to phenomenology for "metatheoretical" support and methodological guidance, but as one confirmed in the broad tradition of philosophical discourse with its own inherited concerns, rules of propriety, and pretensions to totality, who approaches human science research specifically as a topic of philosophy. Whether this difference in orientation precludes a genuine common ground remains to be seen. One can only ever properly speak from the place where one is at, and leave others to do likewise, which at any rate is a precondition of genuine dialogue. "I speak according to my best lights principally before myself," Husserl writes, "but in that manner also before others" (1970, p. 18).

Instead of addressing Osborne's concerns directly in the form that he poses them, my intention is to discuss some broad issues regarding the place of phenomenology in relation to empirical science and philosophy and to explore at a general level some essential dimensions of the phenomenological understanding of essence. In the process, I speak to Osborne's concerns after a fashion, but my chief purpose is to provide a different slant than he upon what is truly at stake, situating his concerns in a broader context and so giving them a different meaning. Though at one level this may serve to dispel some ambiguity, at another it may reveal that ambiguity is endemic to the topic.

\section{The Place of the Question}

As he formulates it, Osborne's overarching concern is "the relation between research practice and phenomenological metatheory" (p. 2). Now, no one committed to phenomenological research is apt to doubt the importance of this concern in spirit. Phenomenologists do need to put their "metatheoretical house in as much order as possible" (p. 2) and to be ever vigilant regarding the concrete connection between theoretical 
self-criticism and the investigation of specific topics. My hesitation on this score lies rather with the formulation itself. My specific worry is that the initial juxtaposition of theory and practice, reflected by the choice of the term "metatheory," harbors positivist assumptions that predetermine the essential bounds and direction of the debate in ways detrimental to phenomenology. Roughly stated, the assumptions I have in mind are: that philosophy (and in this regard phenomenological philosophy would be no exception) is, so to speak, the epistemological "handmaiden" to scientific research, and that as such it is charged to determine in principle the scope and limits of all "scientifically" rigorous knowledge; hence that for each domain of the human (or social) sciences the particular method of inquiry is to be specified and legitimated in principle on independent epistemological grounds prior to any actual research endeavors, such endeavors being methodologically the "application" of preestablished rules and protocols; and that relegated to this epistemological and methodological policing function, philosophy operates under essentially the same epistemological strictures and purview that it invokes. My point here is not that Osborne wittingly assents to all or even to some of these specific assumptions (I doubt that he would, at least not as I have stated them), but that in his very formulation of the issue, he tacitly concedes far too much to them, and so from the outset makes the case for phenomenology less propitious. To render the relationship between methodological self-criticism and phenomenological research as one between "metatheory" and the "practice of a methodology" is in effect to grant, broadly speaking, a positivist conception of method as a definitive set of epistemologically preestablished procedures and applications. The task would then be to get these procedures sorted out in the abstract in order to be secure in all concrete applications, and this for the sake of a genuine, as opposed to spurious, merely speculative knowledge.

Yet this view of method and of knowledge is one at which phenomenologists should balk. In the first place, to accept it means in effect that under a guise of methodological rigor the genuinely self-critical methodological question, that is, the question of the true relationship of one's epistemological standpoint to the essence of the subject matter itself, is decided in advance by fiat, whereas (for lack of a better term) the "onto/epistemological" discourse needed to address that issue properly, the sort of tentative, self-examining discourse in which a radical phenomenology must always engage, is either left unspoken or deemed methodologically illicit. In the event, the demand for methodological exactness drives out all genuine considerations of rigor.

Second, to accept this view is also to commit oneself in principle to a positivistic prejudgment of the relation of philosophy, phenomenology, and research. At the root of the issue is again the question of what it means to assume that there can and must be a prior, independent epistemological determination of the limits of genuine knowledge. By its own self-imposed strictures, such determination has to be free from all on- 


\section{University of Alberta}

tological entanglements and assertions, precisely because among other things it presumes to be the neutral adjudicator of all ontological claims. Now, at one level, this sort of view does have some intuitive plausibility. Only mystics and the most exuberantly playful postmoderns, for example, would knowingly violate the law of noncontradiction and so defy (as Aristotle sets out in "Book Gamma" of the Metaphysics) the minimal condition of intelligible speech (though they too are apt to comply, when it is a matter of making an intelligible case for their own transgressions). Moreover, even those who would insist that ultimately the rules of formal logic have themselves to be ontologically grounded still accept that adherence to these rules is at least a preliminary negative condition of intelligibility and correct assertion. Yet the view I am sketching goes beyond these minimal concessions. By holding that in order for any investigation to be legitimate it must have prior epistemological grounding is in principle to make the standards of that epistemology a positive condition of truth and thereby to grant them ontological force, at the same time ruling out ex hypothesei any ontology that could challenge this epistemology on more radical grounds. Yet, where all "first philosophy" is thereby rendered secondary in theory, in practice it is empiricist standards of genuine knowledge that effectively hold sway. For by maintaining an original essential distinction between epistemological and ontological discourse, and by granting epistemology an absolute priority, no standards for knowledge remain but those of analyticity and objective empirical report, the former guided by the formal, logical canons of consistency and coherence and the latter by those of falsifiability, repeatability, predictability, and technical efficacy. Of course, as I have already suggested, this too amounts to a particular ontology, but one that remains sacrosanct under an assumed name. It is one, moreover, that grants no distinctive place to phenomenology. For, on these terms, phenomenology qua philosophy would be simply the analytic metatheory of empirical research (this meta concealing a host of debatable assumptions), and qua empirical research it would be simply the application of preestablished procedures and protocols.

Since by their own lights phenomenologists are neither positivists nor empiricists, at least not in any standard sense, they are apt to regard themselves as free of the assumptions and implications that pertain to these positions. After all, part of the appeal of phenomenology to human scientists has been its stand against positivism and naive empiricism. Nevertheless, such views are still tacitly in effect when, for example, phenomenologists accept uncritically loose distinctions on the one hand between phenomenology as apparently a metatheoretical endeavor (e.g., what Husserl seems to venture in his various "introductions" to phenomenology), phenomenology as a body of transcendental doctrine concerning the essential constitution of experience and phenomenology as a particular "method" characterized by "reductions," "epochés," "eidetic variations," and so forth, all of which are concerned ostensibly with 
philosophical issues, and phenomenological research on the other hand which applies the "method" to particular concrete topics in actual experience. If we begin in this way, we then need to marry these various perspectives into a unified, self-defining, and self-legitimating conception of phenomenology. But what in the beginning these assumptions put asunder, no amount of metatheoretical finagling after the fact can join together. As a result, it would remain inexplicable how the philosophical discourse which defines and legitimates phenomenology could be one with the philosophical practice of phenomenology which explores the truth and essence of experience and tracks a method. Moreover, it would remain inexplicable how this philosophical work precisely as philosophy could then be "applied" to empirical matters to discover in them something hitherto unknown. In the first case, the sharp distinction between theory and metatheory would itself belie the philosophical adequacy of the stance taken, for at least in terms of its own self-conception and practice philosophy must always ultimately unite whatever strategically it sets apart. In the second case, the step from philosophical knowledge to empirical application would be unintelligible, a metabasis eis allos genus; for insofar as phenomenology is transcendental philosophy it cannot properly be "applied" to experience to establish determinant actualities, since its knowledge concerns that which already determines experience in advance, that is, those essential possibilities that are "higher" (i.e., ontologically and epistemologically prior) than any recordable experiential facts (cf. Burch, 1989, pp. 198-199).

My broad claim, then, is that it is mistaken to approach phenomenology as a particular "method" that can be borrowed from philosophy, in and through a direct application, to enable the human sciences to undertake extraphilosophical research in a way that is distinct from empiricist, quantitative approaches. The error in this is twofold. It tends to misrepresent the essential character of phenomenological knowledge, as if this could be the product, even in part, of simply an alternative way of recording and generalizing from experiential data; and it is to misconstrue the relation of phenomenological practice to theoretical grounds, as if this were an external relation between two epistemologically separate domains. This in turn would serve to grant what phenomenology is obliged to challenge, namely, the broad epistemological framework in which positivists and empiricists operate and from which they apply their standards as absolute. In contrast, my positive point is that phenomenology is philosophical from first to last, and that as such it both admits of no essential juxtaposition of its theory, method, and practice, nor any merely external verification through pure, phenomenologically unmediated data. Though strategically distinct, phenomenology's theoretical self-definition and self-legitimation, its working out of specific methodological procedures, and its investigation of specific topics are not separate inquiries, each of a different logical type, but essential moments in the one ongoing process of phenomenological research. 


\section{University of Alberta}

Though that process begins and ends with lived experience, as venturing a radical comprehension of the truth and essence of lived experience, phenomenological thought is in principle "falsified," so to speak, only on the same terms, that is, by another radical and comprehensive account that challenges a whole conception of the essence and the truth of the matter, in other words, in a confrontation of ontology with ontology.

Given the circumstances that Osborne describes under which he initially formulates his guiding concern (p. 1), it is nonetheless understandable that matters take the turn that they do. Under the sway of natural science research methods, when colleagues question our alternative procedures, they are usually not inviting their own conversion to the alternative whereby they would see the essence of the whole matter differently, but are simply demanding that these procedures measure up to the dominant version of "scientificity," which precludes any fundamental alterity in methods. Not surprisingly, then, when in response to their criticisms we invoke the notion that phenomenology is the study of essences, our colleagues simply counter by asking how those essences are validated by the empirical data, the very form of this question precluding the sort of claim to essential knowledge that we make. To many, such demands are apt to seem "reasonable" enough, since they issue from the hegemonic position that effectively defines (or has until recently) the acceptable limits of contemporary "rationality," with its presumed standards of objectivity, detachment, and empirical sobriety. Thus, for our part, unless we simply decline to play the game-a vain gesture, if we are not already accomplished players in the major league-we tend to be drawn into arguments, the initial terms of which belie the essential difference of the very orientation we seek to defend. In such circumstances, one person's reasonable demand is another's "complex question."

Yet phenomenologists might well insist on the difference, insofar as phenomenology "has the 'a priori' as its theme rather than 'empirical facts' as such" (Heidegger, 1977a, p. 229). Indeed, on this basis, they might insist that phenomenology and empirical science are toto caelo different. To compare them directly on the same terms would thus be as fruitless and misplaced as current debates over creationism and evolution, in which theological symbolizations of the human and the holy are cast on the same level as empirical researches into the paleontological and cosmological records. The discourse of empirical science presumes to be literal, that is, to be descriptively accurate in such a way that a direct verisimilitude is supposed to obtain between its claims and actual states of affairs. In contrast, at the deepest level the discourse of phenomenology, like that of scripture, is "mythical," though not in the pejorative sense of a literally false tale as empiricism would have us believe, but in the archaic sense of a narrative that seeks to gather an integral meaning beyond all objects and objectifications and so beyond the grasp of determinate concepts and finite action, as well as beyond all hard and fast distinctions of literal and allegorical expression. Insofar as it concerns 
the "a priori," phenomenological discourse speaks of what "comes before" or is "earlier" than all empirical facts, and thus not only before all description, explanation and manipulation bound directly to such facts, but also before all metaphor insofar as this presumes such facts already to be known in order then to take us beyond them. Like the Ma'assey Bereshith of Genesis 1, phenomenology is concerned not with temporal beginnings as such but with "origins" in the root sense of the Greek term arche (cf. John 1:1). As is well known, "Husserl would have liked to call philosophy 'archeology' had the term still been available to philosophers" (Spiegelberg, 1969, p. 82). This suggests a topic beyond all empirical research. As "archeological," phenomenology is concerned with what occasions something essentially and rules throughout its being, that in virtue of which something both is and is truly intelligible, as opposed simply to the determinate outset of something, the first term in an actual series of events or material causes to which a thing may be traced back. Heidegger (1980) provides an explicit articulation of this difference: "Beginning is that with which something commences, origin that from which something arises. The beginning is straightway left behind, it disappears in the sequence of events. In contrast, the origin, the source, first appears in the events and is wholly there from first to last" (p. 3). Beginnings, then, occur among beings (i.e., among everything that in principle can be set forth and determined as an object of consciousness), established or conjectured on the basis of objectively calculable relations. Origins are implicit to the manifestness of beings as such and so to everything objectifiable, at once both revealed in beings insofar as they are their disclosive source and yet for precisely that reason also more originally concealed as a whole in favor of the beings made manifest. As a whole, then, origins are not open to an unambiguous, determinate calculation, for they always already precede anything that can be definitively grasped. They have instead to be evoked and recalled, made explicit through imaginative recreation and inscription. The theoretical goal is absolute radical comprehension, though always inevitably as a receding ideal. Doubtless all discourse-_except perhaps the divine word en archebegins somewhere with something. Yet "we humans clearly can never start with the origin [mit dem Anfang anfangen] but we must begin, which means, with something that arises and that originally leads to the source or announces it" (Heidegger, 1980, pp. 3-4). For this reason, in broaching a topic, phenomenology typically begins not as in the empirical sciences with empirical "data" that, all empiricist pretensions aside, typically belong as such to no one's immediate, actual experience, but with understandings that are current, commonplace, and familiar-and yet not so. For phenomenology does not proceed arbitrarily with any old curiosity that happens along, but arises from a perception, however vague or ill defined at first, of something essentially questionable and that makes a topic "topical." Such beginnings, then, are always a presumption to and from what is original, yet one that only the research itself can test in an ongoing circle of understanding. 


\section{University of Alberta}

Of course, it will not satisfy simply to pronounce that phenomenology and empirical science are toto caelo different, as if at a stroke this would resolve our intracollegial disputes over the issue. For in making that pronouncement, phenomenology is implying that its researches are not just different than empirical science but more radical and comprehensive and in that sense more "truthful." This implication is one that empiricist philosophy at any rate would stoutly reject, since it denies the very distinctions in terms of which phenomenology claims this place for itself. Empiricism, for example, rejects the origin/beginning distinction, or rather turns it upside down, locating archai and origins in the unmediated givenness of empirical data, having as such a determinate spatial/temporal location. Thus it likewise denies all genuine ontological a priori, that is, anything that essentially precedes empirical data, since it is just such data that empiricists hold to be absolutely original. Accordingly, empiricism argues that all concepts and judgments ultimately derive from experience. The same is said of language, that is, that its terms and expressions ultimately derive from experience and serve first and foremost a nominative, signifying function referring back to empirical givens or their derivatives. All metaphor and myth is thus a degenerate, dependent, or at least not so serious, employment of linguistic tools, a figured as opposed to literal designation and hence one without an immediate truth value.

Whichever side one comes down on these issues, it should be apparent that more is at stake than simply a dispute about methodological techniques and procedures. Yet also more is at stake than a dispute about what, if anything, comes "before" and what comes "after" experience. More fundamental than these issues are two quite different conceptions of experience itself. To empiricism, experience is composed in the first place of bundles of originally given sensa, it being sufficient for experience that sensa be affectively registered on sense organs and processed through a central nervous system. To phenomenology, experience transcends sensation originally, its essential constitution consisting in a self-constituting interpretive process that originally gives meaning to what can be sensed (cf. Burch, 1990). Beyond this, however, there is an even more fundamental point of dispute. To empiricism, truth resides in the correctness of propositions, that is, in the correspondence of our claims with what is real, which means to the empiricist, ultimately the correspondence with what is objectively present within experience or derived from that presence. To phenomenology, the possibility of such correctness is based on a more original disclosure, that is, on a meaning that precedes and makes possible all objects of experience and all assertions that could correspond to them. In this sense, phenomenological truth does not correspond to beings; it is being itself. Cast in these terms, a number of other differences fall into place. Empirical science proceeds by abstraction and generalization, seeking from fragments of experience both to derive inductively and to test nomothetic regularities in the 
relations among beings, since on an empiricist conception these are the untranscendable cognitive operations performed in experience itself. In contrast, phenomenology is concrete and ideographic, since on a phenomenological account the realization of integral lived meaning in and through situated self-constituting processes is the essential constitution of experience itself. In both cases, then, how one proceeds depends upon how one conceives the essence of the matter itself.

To resolve all of these differences in a convincing way is beyond my present scope and quite likely my talents. Moreover, in such cases where origins are truly at issue, those who are convinced by arguments one way or the other are likely to be those attuned in the first place to the conclusions the arguments enjoin. I can, however, focus the question better by considering more directly Osborne's guiding theme. To counter his colleagues' concerns over phenomenology, Osborne first appeals to the notion that "phenomenological research uncovers essential structures of experience" (p. 1). This is reminiscent of Merleau-Ponty's (1962) famous pronouncement that "phenomenology is the study of essences" (p. vii), a claim typically invoked (as with Osborne) to express the distinctiveness of phenomenology. But to empiricists of the Strict Observance, the study of essences would not amount to much, being at best an exercise in empirical taxonomy in the service of a science, but scarcely the whole of a science proper. This is not to say that empiricists reject any and all notion of "essence." Indeed, for them, some such notion is requisite to human knowledge and communication, being required to take us beyond an unworkable situation in which each individual item of experience is designated by an individually invented proper name (a situation presumed by empiricists to be linguistically original). As effective in knowledge, however, this notion is strictly nominal, an essence in this sense being simply a general term or common name formulated by abstracting from the data of particular experiences. Nothing more is entailed, then, by speaking of "essence" in this sense than that from an initially given exemplary particular items of experience are observed to possess certain characteristics in common and so are grouped as a set. It is in terms of this process of abstracting and relating that empiricists treat the full array of problems of essential determination (e.g., identifying these sorts of figures all as triangles; these figures as isosceles, those as scalene; this crimson, that vermilion, and this cerise all as red, etc.), always starting with a given particular and going on to establish something more general. This is not to deny that for empiricists the things in experience from which these general ideas ultimately derive have a "real constitution" independent of our conventions of word and concept. Nevertheless, empiricists deny that we can truly know anything at all of that reality other than what is found a posteriori among the empirical data and that can be nominally designated. With empiricism, then, all metaphysical specification of "real essences" is ruled out by methodological stricture. It is not surprising, then, as I have already indicated, that 
empiricist investigations into experience are concerned with the delineation and accessibility of an appropriate factual basis, abstracting and generalizing from this in order to establish nomothetic regularities and relationships among observed data. Moreover, by thus "catching things at work," instead of presuming to know a priori essences through contemplation, empiricist investigation seeks knowledge that does "work," that is, that can be put to use to make things work to our supposed benefit (cf. Jonas, 1966). This is consistent with what I previously claimed about truth, namely, that for empiricists it consists in the conformity of our claims with objective states of affairs, a conformity that is, moreover, sufficiently confirmed if the knowledge made up of such claims proves technically efficacious.

In philosophical terms, phenomenology's countercomplaint against empiricism is not that it is stubbornly hypercritical, restricting genuine knowledge to what originates and terminates in supposedly hard empirical "data," but that it is not critical enough, taking too much about knower and known and their interrelation simply for granted. Thus it is not that empiricism simply attempts an illicit reductionism (as I too often carelessly tell my students), but that it proceeds too simplistically from what it takes to be evident common sense (or at least the evident common sense of our culture). "That all our knowledge begins with experience," Kant (1929) says on empiricism's behalf, "there can be no doubt" (p. 41). Less certain, but no less commonsensical, is the belief that all knowledge originates from experience, coming to us ultimately through the five senses. To deny that there is any genuine knowledge that extends beyond the bounds of experience (i.e., any purely transcendent metaphysical knowledge) is simply the sensible and legitimate extension of these commonsensical beginnings. Yet phenomenology questions whether these beginnings are self-evidently and truly original. "Even though all our knowledge begins with experience, it does not follow that it all arises from experience" (Kant, 1929, p. 41). Phenomenology questions the empiricist inference that it does from two convergent directions.

First, far from accepting that there are in experience sense "data" that are an obvious, original given and the foundation of all knowledge, phenomenology asks how anything purely and simply given through the senses could by virtue of the senses alone amount to experience or be specified and elevated to knowledge. Beginning with Kant, the form of the argument on this point is basically the same, that is, to show against empiricism that the very possibility of experience has a priori conditions that as such cannot originate from experience. To point out even the simplest experiential data - this here and now; that there and then-requires a cognitive structure that cannot originally be derived from experience by an abstraction from given particulars, since it is the very medium through which particulars come to be objects for us as such in the first place. In other words, an empirical "datum" can become an 
object within experience, and hence be an empirical datum (which means to be situated as a datum within a system of data, for otherwise it would dissolve irretrievably into an undifferentiated plenum of sense), only because it is constituted as such by and for an experiencing subject. Without this constitution not only would we be unable to say what we experience and know, to point it out to others, or to locate and preserve it in memory, but for the same reasons we would not have experience in the first place (cf. Burch, 1990).

Second, what empiricism claims with respect to the "objects" of knowledge, it has to say pari passu of the "subject." It seems commonsensical enough to claim that we have immediate "knowledge" of our own feelings and psychic states and that this knowledge is empirical. But if all knowledge comes originally through the senses, it is somewhat less evident wherein lies the relevant "inner sense" through which we know ourselves and hence know that it is " $I$ " who has knowledge. According to tradition, modern subjectivism confronts an egocentric predicament: I can know immediately my own feelings, and can immediately observe the behavior of others. But I can know the feelings of others, and even the fact that there are others like me, only by an inference from objective observations. Empirical social science governs itself accordingly. Dismissing any presumption to know the inner life of the other directly, it maintains instead that all genuine social knowledge is rooted in and limited by objective, empirical observation. On this score, however, a puckish phenomenologist might well suggest that for empiricism exactly the reverse is true, that is, that unbeknown to itself it is actually caught, as it were, in an object-centric predicament. For, if it maintains that what we immediately and certainly know comes to us through the five senses, then it is evidently the empirical world of sense data and not the self that we directly know, since one's "self" is not found as a specific item among the sense data. On these terms through observation of the data given through the five senses, we would first classify certain objects according to regularities of appearance and behavior as belonging to the set "human being." Then, by means of an inference from the observed regularities of our own behavior and appearance, we would include ourselves as a member of that set. Thus, paradoxically, I would know others as selves directly by observation and abstraction; I would know my own inner life as my own only by inference. Now, however ridiculous this scenario may seem, it has a certain plausibility, since an empiricism that limits the origin of genuine knowledge to sense data has a difficult time explaining how self-knowledge is no exception. Indeed, in a famous passage, Hume (1888) denies that it is. "When I enter most intimately into what I call myself, I never catch nyself at any time without a perception, and never can observe anything but the perception" (p. 253). He then draws the logical conclusion: It is "the successive perceptions that constitute my mind." With good justification, Hume is eager here to exorcise the metaphysical fiction of a ready-made substantial self, the proverbial 


\section{University of Alberta}

"ghost in the machine." But in his eagerness, he does not ask about the constitution of the "I" that first does the "entering," "catching," and "observing," nor how an original, external juxtaposition of perceptions could then amount to a self-conscious experiential sequence. All identity may well be an association of ideas, as Hume argues, except the identity of the self that does the associating. What phenomenology demonstrates is that this identity must be a "self-constituting" process more original than all empirical data and all abstractly juxtaposed perceptions (cf. Burch, 1990).

\section{The Question of Essence}

To get a better sense of the distinctiveness of phenomenology as the study of essences, we need to situate in positive terms where phenomenology stands on this question of essence itself, and to do that we need to see how it situates itself in the history of the interpretation of essence. This requires, if only briefly and superficially, that we return to Platonic beginnings, for on this issue it is Platonism that provides the terms with which phenomenology begins.

As virtually any history of philosophy will tell us, Plato appropriated to the center of his thinking an everyday Greek noun eidos to serve a twofold philosophical purpose. In his vocabulary, an eidos was that which was sought in answer to all questions (themselves first philosophically exalted in Plato's Socratic writings) of the form "what is (e.g., piety, justice, friendship, etc.)?" It signified that in virtue of which many things are said to be truly the "same," that is, the character, nature, or quality in respect of which they do not differ, which makes them all instances of a kind, by which they can be named as such and be judged. The word eidos was at the same time Plato's term for all that which is really real, not its truth or being, strictly speaking, but the very thing itself, in which being and truth are convertible. To keep one's eye fixed upon the eide was thus the Platonic version of zu dem Sachen selbst.

The etymology of eidos provides a significant clue as to how these "matters" might be understood. In everyday Greek, the noun eidos meant "that which is seen" or "makes itself manifest to seeing," and even more commonly the "form," "shape," "figure," or "look" in virtue of which what is seen is visibly differentiated. This noun derived in turn from the verb eido meaning "see," yet also in its perfect and pluperfect forms, "know" (e.g., "I have seen"= "I know" and "I had seen"= "I knew"). Mindful of these etymological origins, Plato characterizes the really real, an eidos, as that which is preeminently seeable and what is preeminently seeable as that which is most properly knowable. Furthermore, what is preeminently seeable and knowable is that which presents itself to sight as uniformly one, which is to say, as determinate, selfsame, and unchanging, without ambiguity or residual opacity. In general, it is how something shows itself to sight that characterizes for Plato at once its truth (aletheia) and its being (on). To show itself as many, that is, ambiguously 
and nonuniformly, marks the inadequate and dependent truth/being of what merely becomes. To show itself as one characterizes the truth and being of what is really real, in other words, of the eide. It is in virtue of the eidos that the particular existent thing both is and is intelligible, that we are able to name many existent instances as the same and hence designate them as instances, and to judge the particular instances as genuine or sham.

The histories of philosophy also record how this doctrine has been appropriated. Plato is typically portrayed as advancing a "two worlds" dichotomy (the terms of this juxtaposition having their most famous, albeit figurative, expression in the cave allegory of Republic VII), the main focus of concern being how the eide relate to existent particulars. Accordingly, whereas the term eidos was for Plato at once the name for the really real itself, "the most beingly being" (to ontos on) or simply "that which is" (ho estin), in its complete integrity, and for the common characteristic of all possible mutable instances of the thing, it is this latter sense that comes to take precedence in the tradition. The common characteristic specifies "what" the thing is as such, as opposed to "that" it is, or in later terminology, its "essence" as opposed to its "existence." "Essence" as "whatness" names that which something like the existing thing can be, if it exists, for example, that which makes any and all trees possible as tree, without regard to whether this or that tree actually exists. That this notion of eidos as essence should take precedence is not surprising. It does so in everyday experience and cognition in virtue of the necessity for general naming. Doubtless, this necessity is a fundamental dimension of our being human and a source of our peculiar "dominion" (cf., Genesis 2:19-20). However, though we may as human all have this need to order experience under general names, that is, to abstract from experiential realities in order to control them by representing them to ourselves, the assumption that the names sought are strictly abstract and universal and hence removed from any concrete engagement in a particular place is a residue of metaphysics in the everyday attitude that prevails in our culture (I do not say "in the natural attitude," since to assume that there is such an attitude is itself a metaphysical residue). In philosophical discourse, the separation of "whatness" and "thatness" and the precedence accorded the former coincides both with the privileging of "sight" in the domain of genuine knowing and the need to name the eide separately. In the extreme, then, translators and philosophy professors will happily speak of Plato's theory of "forms," and fledgling undergraduates will then try to imagine visible archetypes housed immutably in some "heavenly place." This privileging of sight metaphors and of the designative function of naming favors a conception of the real as what is objectively determinable and specifiable, a precise static form or formula having an abstract universality. (In this regard, for example, Descartes' equation of true being and real being in terms of clear and distinct ideas as certainly known is not a repudiation 


\section{University of Alberta}

of Platonism but a simplified fulfillment.) "Formism" as a "root metaphor" for any research owes its original sense to this Platonic doctrine.

The other dimension of Platonism relevant to the topic at issue is the famous Meno paradox (Plato, 1902, p. 80e). It runs: "How can I search for knowledge, unless I know what it is for which I am searching? Otherwise I will not know what to look for, nor then how to proceed to look. But if I know what to look for, then I need not search, since I already know. The search for essential knowledge is thus either impossible or superfluous!" The Platonic answer to this dilemma, which is also in principle the answer of phenomenology, is that the search for essential knowledge is possible only as a form of "recollection," wherein what is only vaguely or tacitly known to begin with is explicitly explored and mapped.

Phenomenology begins with the traditional determination of essence as a form separate from existence. "According to ancient doctrine, the essence of a thing is considered to be what the thing is" (Heidegger, $1977 \mathrm{~b}$, p. 288). Thus, for example, "when we are seeking the essence of 'tree,' we must grant that what pervades every tree as tree is not itself a tree that can be encountered among all the other trees" (p. 287). On this point, phenomenology, empiricism and rationalist metaphysics are of roughly the same opinion. They differ, however, concerning the derivation and legitimation of this "what" and so understand its ontological status differently. In this regard, though empiricists and rationalists hold opposing views, they cast the problem on the same level. Whereas empiricists claim that this "what" is simply a form derived by separating from sense particulars all circumstances of their real existence, the legitimation of this "what" resting in further observation, rationalists claim that the existence and knowability of the sense particulars presupposes the form, the legitimation of which is a matter of a priori reasoning. All debates about immanent or transcendent formism, and about realism or nominalism, get cast at this level.

Though typically it begins with this notion of essence as "whatness," phenomenology moves beyond this level of argument to explore essence more originally. The first step in this move consists in phenomenology's appropriation of the so-called "Copernican hypothesis," that is, the venture to examine whether and in what degree objects conform a priori to our knowledge rather than assuming absolutely that all knowledge must originally conform to objects, be they empirical or ideal (Kant, 1929, p. 22). Three aspects of this hypothesis are particularly relevant to the present discussion, all having to do with the basic principle that where something is known a priori that depends upon something being contributed a priori by the knower.

First, on the issue of essential knowledge, phenomenology, like its Kantian antecedent, seeks a "critical path" between rationalist metaphysics and empiricist skepticism. Like empiricism, on the one hand, phenome- 
nology does not accept as legitimate or legitimatable any claim to a priori essential knowledge that extends beyond the bounds of possible experience. No matter how coherent internally, such claims lack experiential verification and so amount at best to an ideal construct, one among many possible such constructs, and not to a demonstration a priori of reason-inreality. On the other hand, like dogmatic metaphysics phenomenology does lay claim to a priori essential knowledge and hence purports to know something of beings prior to their being given within experience. Thus, on the one hand, insofar as "phenomenological truth is transcendental truth" (Heidegger, 1977a, p. 38), and so is a priori, knowledge of it cannot be "produced inductively" (Osborne, p. 11) from experience but must in some sense always already have been known prior to experience. On the other hand, for phenomenology to "maintain a perspective on the lived human experience" (van Manen, 1983-1991) means methodologically that lived experience is the terminus a quo and ad quem of phenomenological theorizing, at once the beginning and the origin. Phenomenological truth must have an existential matrix in lived experience "in order to have reality of any kind and to be furnished with what one may term experiential verification" (Fackenheim, 1967, p. 227). Thus, in contrast to metaphysical truths of reason, phenomenological truth is not an innate form absolutely independent of experience and accessible by reason alone, but a context of meaning in virtue of which experience is constituted as such and which can itself be known on the basis of this constitution. In contrast to empirical truths of fact, phenomenological truth is not tested against this or that body of empirical data, but is verified in terms of the possibility of experience, and hence as "coming before" experience as its meaning and ground, experience that in its essential constitution has already a transcending dimension.

Second, the Copernican hypothesis turns on the general thesis that "reason has insight only into that which it brings forth [hervorbringt] after a plan of its own" (Kant, 1929, p. 20). Broadly speaking, it is in terms of this thesis that phenomenology understands the intuition of formal essences and affirms the possibility, or rather the necessity, of eidetic insight. "The essence proves to be that without which an object of a particular kind cannot be thought, that is, without which the object cannot be intuitively imagined as such. This general essence is the eidos, the idea in the Platonic sense, but apprehended in its purity and free from all metaphysical interpretations" (Husserl, 1973, p. 341). Against empiricism, on the one hand, phenomenology denies that such essences are originally induced ex post facto from pure empirical data, claiming instead that every perception (or imagining) is originally a perception (or imagining) of something as something, and in that measure always already involves an eidetic intuition. We are first able to intuit an object only because in the very act we intuit it as something, that is, concretely as a meaningful presence in a perceptual field of other meaningful presences, and not abstractly as a pure sensum or bundle of sensa. Yet, in 


\section{University of Alberta}

intuiting the object as such, we are intuiting an essence, seeing at once, for example, both this tree here and now as $a$ tree as well as a form of all possible trees. Now, as most empiricists would have it, the particular intuited tree in its actual singularity is itself nominally the essence in the form of a given determinate exemplar against which subsequent objects are judged as to their arborescence. In contrast, the phenomenological thesis is that the eidetic insight is an integral a priori dimension of the very experience of the determinate object, yet qua eidetic it is an insight into the possibility of such objects, not just into the singular form of the one given object. Moreover, we can intuit an essence in this sense, phenomenology claims, only because the object has been constituted essentially in advance by the knowing subject, allowing it to be intuited as such. The operations of comparing, abstracting, and imagining on the basis of empirical intuitions already presuppose that experience has been eidetically organized in this way. Against rationalism, on the other hand, phenomenology claims that this a priori eidetic organization is not the product of innate ideas imprinted on consciousness as pure forms of possible concrete particulars and accessible a priori as objects of pure reflection. Instead, phenomenology claims that whatever can be objectively intuited, either empirically or eidetically, presupposes a priori a ground, that is, a horizon of integral meaning, operative in experience, and which makes possible whatever figure is given as it is given, even though as a rule that ground itself is only tacitly known. Thus, whereas rationalism, for example, would hold that we have in posse as rational beings an a priori idea of triangle as a discrete essence, one that we make explicit through reflection independently of experience, phenomenology holds that the triangular figure is intuited as such and the formal concept of triangle constructed on the basis of an a priori determination of spatiality rooted ultimately in lived experience. In general, then, an object can be given as such, variations and iterations can be imagined and discovered, future instances can be anticipated and identified, similarities abstracted ex post facto, and our general concepts made more precise only in terms of an a priori horizon of meaning within which objects appear in a specific way. It is this integral horizon that affords the ground of essence as eidos and is the basis for all so-called "methods" of essential seeing.

Third, what is operative a priori in experience, though not objectively given, is explicitly known according to the same principle as governs our knowledge of the eidetic intuitions it grounds, namely, that we know a priori what in some sense we "bring forth" a priori. As I have said, eidetic intuition is possible on the basis of an a priori horizon of integral meaning, that is, in phenomenological terms, a "world," which always already organizes data in a characteristic way. We know that world as such is not a fixed object or structure to which our understanding must simply conform, but as a context of meaning in whose essential constitution we share and to which objects conform a priori. We share in that constitution 
essentially insofar as it is one with our self-constitution. Admittedly, in some spheres and levels, the constitution of the world is an ideal construct of an explicit science and serves to delimit a specific range of possible objects of explanation. For example, the world of Euclidean geometry is constructed from definite postulates and definitions that delimit a world in which, for instance, triangle is then a precisely determined ideal object. Yet the meaning and ground of that construction lies ultimately in the spatial constitution of the world of everyday lived experience. (When, for example, Husserl [1970] speaks of a "crisis" of European sciences, he has in mind, partly, the failure to show how the sciences are ultimately founded in the constitution of the life world. It is for this reason that, in spite of the technical empowerment they afford, these sciences are said to have lost their meaning for life.) A "world" in this phenomenological sense is that on the basis of which objects are always already understood as such and accessible in the first place, however they may then get explained in detail. But this is just how phenomenology understands the being of beings (cf. Burch, in press). This implies that for phenomenology the forms of transcendence that constitute the being of beings are ultimately one with the transcendence that is our own self-constitution, our being-in-the-world. It is this essential interconnection that makes possible our a priori knowledge and lies at the basis of all phenomenological reflection. In affirming this interconnection, however, phenomenology "does not say that being is a product of human being" (Heidegger, 1977b, p. 216), for there is always more to our being-in-the-world as a being among beings than any human willing, whether singly or collectively, can simply posit, delimit, or create. Still,

we always say too little of "being itself" when in saying "being" we leave out its presence in [An-wesen zum] the human essence and thereby misjudge that this essence itself co-constitutes [mitausmacht] being. We also say too little of human being if, in saying "being" (not human being), we set human being apart and only then bring that which has been set apart into relationship with being. (Heidegger, 1958, p. 75)

In this respect, the ambiguity of phenomenological method is from the first an ontological issue.

\section{In Lieu of a Conclusion}

Among the once popular light-bulb jokes, there was one that ran: "How many philosophers does it take to screw in a light bulb?" Answer: "That depends upon what you mean by 'light bulb." My "reply" to Osborne has taken roughly the same form. To the question, "How are we to understand the practice of phenomenology as the study of essences?" my response has been, "That depends upon what you mean by 'essence." The need to address this latter concern is what occasioned my excursion into the history of philosophy. At issue was the essence of phenomenology and ultimately the essence of essence. 


\section{University of Alberta}

To explore properly the manifold yet unified sense of "essence" would require a thorough phenomenological investigation in its own right. Suffice it here simply to rehearse some key points relevant to the topic we are considering. To phenomenological theory, as I have said, "essence" means first but not originally eidos or "whatness," that is, a static form that can be objectively delimited. In this "formal" sense, essence can be presented "tangibly" in concepts, images, or propositions. This is the domain of ontic truth, that is, of the manifestness of beings as determinate objects of consciousness, which in turn is the ground of propositional truth, that is, of the correspondence of our judgments to objective states of affairs. But ontic and propositional truth have a more original ground in ontological truth, that is, in the disclosure of a "world" of meaning that first makes possible the manifestness of beings as such. At this level, essence means first and foremost the a priori conditions of the possibility of beings as such. Yet, insofar as this possibility is to be found not merely in a static structure built into consciousness a priori and imposed on a sensible manifold, but in the whole ongoing historical, interpretive process of our being-in-the-world, then essence takes on a more original verbal sense, denoting the whole way in which a matter comes significantly to presence and endures in the course of experience, prior to all objective determinations and abstractions. (Something like this verbal sense of essence has been evident in the history of philosophy, for example, in Aristotle's use of the term ousia, meaning literally "already having been," for being/essence, and in Hegel's claim that "Das Wesen ist das Gewesen"- that "essence is what has been.") Essence in this original sense has at once both ontic and ontological significance. The essence of the discrete thing as its enduring significant presence in our understanding leads both synchronically and diachronically to worlds of meaning that constitute the essence of being. Taken individually, questions about the legitimacy and universality of phenomenological insights must be broached differently at each of these different essential levels, the last being the most original. Still, the essence of phenomenological truth lies not in "isolated propositions and slogans" but in the whole "way of thinking" (Heidegger, 1977b, p. 287), that is, in what is disclosed in the whole process of thought as it moves forward and backward through these various levels.

The foregoing considerations do answer Osborne's specific question (p. 11), but obviously not in the direct manner in which he might have hoped. Osborne asks: "What is the relation between a priori eidetic structures and inductively produced structures of meaning of human experience?" On the one hand, as I have already claimed (but only claimed, since a complete argument would have required a much more detailed account), we are able to intuit eidetic structures and forms only on the basis of a "world" of meaning that in some sense we always already know prior to the eidetic intuition and in terms of which "data" are always already organized. On this account, eidetic intuitions do not simply come ex post 
facto from a deliberate cognitive exercise, but are already constitutively operative in experience as such, and it is for that reason that they can be intuited a priori. On the other hand, as I have also already claimed, it is not the business of phenomenology to produce meaning structures inductively, for on its own terms the topic of phenomenology and its understanding of what is essential "come before" any meanings that could be inferred from samples of particulars. Where phenomenology purports to make such inferences, it concedes to empiricism its basic terms of reference and so must meet empiricist standards of rigor. Yet to do so is to deny its own place.

Of course, our more skeptical colleagues might still ask wherein lies the legitimacy of these phenomenological claims to essential knowledge? In the face of much-bruited demands for "objectivity" and verification, phenomenological procedures may well seem suspect. Yet it may be that it is these demands that are truly suspect and not our procedures. Indeed, at the level of what is truly essential, we "can provide no credentials for what we have said that would permit a convenient check in each case whether what we say agrees with "reality"' (Heidegger, 1971, p. 186). For the reality spoken is not a static, objective given to which our claims could then simply be compared for the sake of "correctness" (the very possibility of such comparison presuming in any case a knowledge that transcends the terms related). Rather, between that reality and our being-in-the-world, including our theorizing, there is a relation of mutual dependence, such that our theorizing itself shares in the constitution of that reality. In our theorizing, then, there is no extrication of the "matter itself" from the modes of our interpreting it, with their varied histories and locales. "To be sure, [such] thinking also knows concepts. These differ, however, from scientific concepts not only in regard to the degree of generality. [They] are in their essence of a different sort insofar as that which they comprehend and the comprehending itself remain in an original sense the same" (Heidegger, 1958, p. 67). Moreover, in contrast to the objects of scientific research, the reality interpreted phenomenologically is essentially nonobjective, that is to say, not merely subjective but transcending the subject/object dichotomy and serving as its ground. In considering this ground, then, phenomenology places itself beyond all straightforward objectivism/relativism problematics. This means, of course, that the truth of phenomenology does not reside exclusively nor principally in a "transcendental analytic" of the sort that sets forth universal and necessary structures of empirical knowledge through an objectifying reflection. Nor, then, do its explorations admit of a straightforward "transcendental deduction," that is, a demonstration that all possible objects of experience are subsumed under this singular set of abstract structures and no other. Instead, phenomenological theorizing moves from what comes first in lived experience, that is, from a familiar determination of what things are, to that which is more original, that is, to the subjective grounds of objects of experience, and 


\section{University of Alberta}

thence to the situating contexts of all forms of the subject/object dichotomy and its ancillary functions. Yet it must also complete the circle of this investigation, returning to the subject/object dichotomy, and thereby to the merely correct and seemingly given, though now reinterpreted more originally.

Still, there are at least three related respects in which this "method" does seem to pose difficulties. First, phenomenology is theory only insofar as it pursues truth with a universal intent. In this formal respect, it would seem to meet opposing theories on a common ground. Indeed, in the empiricist accusation that phenomenology universalizes illicitly, and in our private worries that this might well be so, this ground is evident. But the genuine difficulty here is not that phenomenology might indeed universalize illicitly, but that phenomenologists will take this merely formal determination of a common ground to be decisive and in that way misunderstand their own project. For the decisiveness of this common ground is based upon a set of assumptions that phenomenology should properly reject. It assumes, for example, that theorizing both begins and originates with what is simply particular and thence by means of a universalizing abstraction from selected "data" ventures to establish something more general. Ideally, the place of the theorist in this process is "u-topian," that is, it is nowhere in particular, since one seeks to maintain an objective, disinterested perspective on all particulars. The universality that is thereby posited is an abstract universal, that is, an empty form derived from experience, that in being so derived is posited as a determinate object for our knowledge, and that holds indifferently of all the particulars within its extension. The methodological demand that this imposes - one which phenomenology is thought unable to meet-is to establish the scope of this extension, in other words, to determine the generality of the form, plotting the "correct" range of its experiential "application" both within and across differences, for example, of gender, class, background, culture, and so on. Now, it is quite true that phenomenology does not meet this demand. Yet it fails to do so not from some inherent deficiency, but because it rejects the very terms in which the demand is posed. On its own terms, the beginning and origin of phenomenological theorizing is the concrete situation in which the theorist finds herself, a situation always already universal in its essential constitution, the task being to explore the truth of that situation from within. The proper place of the phenomenological theorist, then, is just that situation itself, since there is no other, and nothing, as it were, that can be for us outside it. To borrow here a Platonic image in order to reject it, the situation is not properly rendered as a particular cavernous domain juxtaposed to all other possible such domains that one can imagine or encounter, a merely parochial outlook that in theory we must escape absolutely, along with all other such outlooks, to reach a radically universal and hence transcendent truth. Rather, the situation is the very place wherein essential, universal truth is realized (in both senses of "realize") 
and comprehension is at all possible. Thus, in the essential theorizing that arises from this place, "we do not want to get anywhere. We would only like, for once, to get where we are already" (Heidegger, 1971, p. 190). Yet the universality disclosed in this theorizing is not an abstract universal simply juxtaposed to particulars, but rather a concrete universal, that is, an encompassing meaning always already implicit to and making possible experience. This meaning precedes essentially all possible objects of experience and all relations to others, and thus comes before all possible objectifications and abstractions, and all particular understandings or misunderstandings between subjects. Thus, though typically we do recognize the experience of others as different from our own and seek communicatively to render that difference inessential in a truly universal perpsective, it is always already the situation in which we find ourselves that is the a priori horizon for all such efforts. As universal, this horizon encompasses the experiential content of the particulars within its domain. As concrete, however, it does not apply indifferently to particular instances as an abstract form, but encompasses the particulars in an individual context. There is in this a dialectic of sorts. For the reality of the concrete universal is mediated essentially in and through the particulars it encompasses; and the particulars encompassed come to be particulars in and through the universal. The middle term in this dialectic is thus an "individuality" in which universal and particular are not just externally related but realized as one. Though such talk is admittedly a bit abstruse, its implications for phenomenological method are, I hope, less so. The concrete universal phenomenology discloses is never properly a determinate object of knowledge that could be judged as to its generality in relation to given particulars. It is rather an indeterminate and preobjective context of meaning always already in play in all such determinations and judgments. Moreover, though it is individual, it is not juxtaposed to other such contexts as one particular to another, but is the a priori horizon for whatever the theorist can think or know, and for whatever particulars she can encounter. What is precarious about phenomenology, then, is not that it must move from the merely particular to the wholly universal by some dubious method of eidetic insight, but that the universality it seeks to comprehend, though always essentially in play, also always essentially eludes precise and final determination.

Second, as phenomenology moves beyond the subject/object dichotomy, its basic terms of reference transform and converge. Thus, for example, the essence (i.e., the eidos and the a priori condition of possibility) of truth (i.e., of correspondence) shows itself at a deeper level to be the truth (i.e., the meaning-disclosure) of essence (i.e., the manner in which a matter comes meaningfully to presence and endures). This proves difficult, since at this level what is distinct-truth, essence, meaning, as well as world, being, the essence of human being-is not separate. To traditional philosophy, this looks like a confused conflation of meaning, in- 


\section{University of Alberta}

sofar as the tradition advances the principle that what is distinct must essentially be separable. What phenomenology holds in contrast is that this principle is itself an inappropriate residue of objectivizing thought and not an essential reflection of the matter itself. Once beyond the subject/object dichotomy, it also proves difficult to make clear how in principle the movement back to that level, that is, from truth as meaning to truth as correctness, is to be accomplished and what one is then to make of the "correct" in the light of the previous course of thought. Though it may seem to critics like a dodge, phenomenology insists that there can be no such clarification in principle, since what one truly makes of essential thinking and the transformations its effects can only be discovered in medias res.

Third, as I have characterized it, phenomenological theorizing has an inherent ambiguity. On the one hand, it seeks to know the ultimate situating context of our lived experience, but in itself is a transformation of that context. Between the phenomenological truth we seek to know and the phenomenological knowing itself there is an essential correlation, our self-constitution being part of the constitution of that domain of truth. On the other hand (cf. Fackenheim, 1961, p. 90), the context that situates us humanly, precisely in doing so, in truth always inevitably eludes absolute comprehension, or rather is comprehended objectively, certainly, only on the basis of a pseudo-detachment from our concrete lived experience. At the highest level, then, phenomenological knowledge is a "learned ignorance" of sorts - "ignorance," because it knows the totality it seeks to comprehend always essentially eludes its certain, objective grasp; yet "learned," because it recognizes that totality as such and knows the ground of its ignorance. "In this realm, one cannot prove anything, but one can show a great deal" (Heidegger, 1957, p. 10).

No doubt to empiricist thought these limits to phenomenological understanding will always appear to be simply limitations, that is, merely negative restrictions to a blanket-imposed standard of objectivity, conceptual precision, and abstract universality. To phenomenology, in contrast, they mark the very boundaries within which essential thinking is possible and wherein it comes into its own. From a phenomenological perspective, then, the deeper issue is not whether we can meet externally imposed standards of exactness, which in any case we consider inessential and inappropriate, but how the essential boundaries of our thinking and being can be plumbed and comprehended by beings who are in their very selfhood finite and situated. In this regard, it is the debate with the metaphysical tradition that is more profound and exigent. At issue is whether, as metaphysics claims, the true origin of essential knowledge lies in the infinitude of the divine perspective, an infinitude that must be definitively realized by us, if our claims to universality and transcendence are not to dissipate into mere finitude; or whether, as phenomenology claims, it lies in a finite transcendence that discloses "being" different essentially from all beings and so beyond our absolute comprehension, 
but which at the same time is the indeterminate positive domain wherein alone beings are manifest and human comprehension is truly possible. In this debate, phenomenologists might take heart from Kant's affirmation in the wake of his own critique of traditional metaphysics. "Although we had contemplated building a tower which should reach to the heavens, the supply of materials suffices only for a dwelling-house, just sufficiently commodious for our business on the level of experience, and just sufficiently high to allow of our overlooking it" (p. 573).

\section{Note}

1. This article is a reply to Osborne (in press) published in this volume of Phenomenology + Pedagogy. All references to Osborne are to this article, and the page numbers shown correspond to the draft copy of the article.

\section{References}

Burch, R. (1989). On phenomenology and its practices. Phenomenology + Pedagogy, 7, 187-217.

Burch, R. (1990). Phenomenology/Lived experience: Taking a measure of the topic. Phenomenology + Pedagogy, 8, 130-160.

Burch, R. (in press). Phenomenology and human science research reconsidered. Phenomenology + Pedagogy, 9.

Fackenheim, E.L. (1961). Metaphysics and historicity. Milwaukee: Marquette University Press.

Fackenheim, E.L. (1967). The religious dimension in Hegel's thought. Boston: Beacon Press.

Heidegger, M. (1957). Identität und Differenz. Pfullingen: Neske.

Heidegger, M. (1958). The question of being. New Haven: College \& University Press.

Heidegger, M. (1971). Poetry, language. thought. New York: Harper \& Row.

Heidegger, M. (1977a). Sein und Zeit. 13 Aufl (with the author's marginal notes). Tübingen: Niemeyer.

Heidegger, M. (1977b). Basic writings. New York: Harper \& Row.

Heidegger, M. (1980). Holderlins Hymnen "Germanien" und "Der Rhein". Frankfurt: Klostermann.

Hume, D. (1888). A treatise on human nature. Oxford: Oxford University Press.

Husserl, E. (1970). The crisis of European science and transcendental phenomenology.

Evanston, IL: Northwestern University Press.

Husserl, E. (1973). Experience and judgment. Evanston: Northwestern University Press. Jonas, H. (1966). The practical uses of theory. In The phenomenon of life. In ( $\mathrm{pp}$. 188-210) New York: Dell.

Kant, I. (1929). Critique of pure reason (N.K. Smith, Trans.). New York: St. Martin's Press.

Merleau-Ponty, M. (1962). Phenomenology of perception. London: Routledge \& Kegan Paul.

Osborne, J.W. (in press). Is there a metatheoretical ambiguity in the practice of phenomenological research methodology in contemporary psychology? Phenomenology + Pedagogy, 9.

Plato. (1902). Platonis opera, III (J. Burnet, Ed.). Oxford: Oxford University Press. Spiegelberg, H. (1969). The phenomenological movement, Vol I. The Hague: Nijhoff. van Manen, M. (1983-1991). Masthead. Phenomenology + Pedagogy, 1-9. 